\title{
Inge Kroppenberg
}

\section{Privatautonomie von Todes wegen}

Verfassungs- und zivilrechtliche Grundlagen der Testierfreiheit im Vergleich zur Vertragsfreiheit unter Lebenden

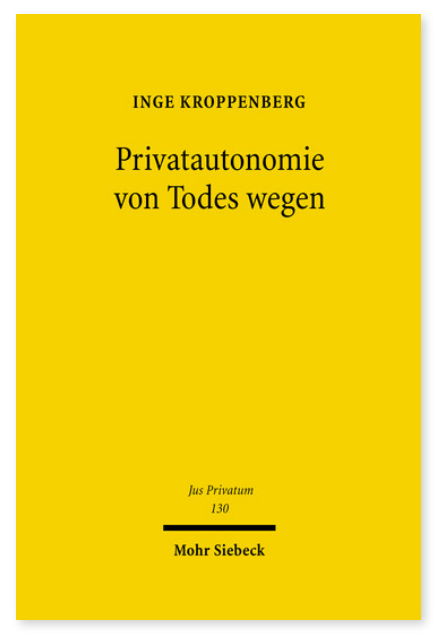

2008. XVI, 410 Seiten. JusPriv 130

ISBN 978-3-16-151207-0

DOI 10.1628/978-3-16-151207-0

eBook PDF $119,00 €$

ISBN 978-3-16-149190-0

Leinen $119,00 €$
Inge Kroppenberg nimmt die gestiegene Bedeutung der Testierfreiheit in der »Erbengesellschaft« zum Anlass, die dogmatischen Konturen der Gestaltungsbefugnis von Todes wegen herauszuarbeiten. Ihre Untersuchung trägt in dreierlei Hinsicht zu einem neuen Verständnis bei: erstens, indem sie die Testierfreiheit als zivilrechtliches Prinzip vor einer zu stark verfassungsrechtlich geprägten Anschauung in Schutz nimmt. Die Gestaltungsbefugnis von Todes wegen wird in der verfassungsgerichtlichen Rechtsprechung als Verfügungsbefugnis über den Tod hinaus beschrieben. Damit erscheint sie als Fortsetzung des Rechts der Lebenden mit anderen rechtsgeschäftlichen Mitteln und wird zudem mit der Vorstellung eines »Leistungseigentums « verknüpft. Es zeigt sich des Weiteren, dass an die Gestaltungsbefugnis von Todes wegen Strukturmerkmale heran getragen werden, die aus dem Recht der Lebenden stammen, im Erbrecht aber Fremdkörper sind. Das gilt zum einen für den erbrechtlichen Typenzwang, der in Anlehnung an den sachenrechtlichen konzipiert wird. Es gilt aber vor allem für die Anleihen, die beim lebzeitigen Vertragsparadigma gemacht werden und die diachrone Struktur des erbrechtlichen Rechtsgeschäfts außer Acht lassen.

Drittens ist es der Autorin um ein genuin rechtsgeschäftliches Verständnis der Testierfreiheit zu tun. Das klingt selbstverständlich, ist es aber nicht. So behaupten familienerbrechtliche Deutungen der Gestaltungsbefugnis von Todes wegen einen Leitbildcharakter der gesetzlichen für die rechtsgeschäftliche Erbfolge. Ihre Interpretation als besonderes Persönlichkeitsrecht des Erblassers zur Todesverarbeitung verengt schließlich den privatrechtlichen Freiheitsraum von Todes wegen inhaltlich auf eine Reflexion über Mortalität.

Inge Kroppenberg Geboren 1968; Studium der Rechtswissenschaften an der Johannes Gutenberg-Universität Mainz; 2000 Promotion; 2005 Habilitation; Vertreterin der Professur für Antike Rechtsgeschichte, Europäische Privatrechtsgeschichte und Zivilrecht an der Universität Frankfurt am Main.

Jetzt bestellen:

https://mohrsiebeck.com/buch/privatautonomie-von-todes-wegen-9783161512070?no cache=1

order@mohrsiebeck.com

Telefon: +49 (0)7071-923-17

Telefax: $+49(0) 7071-51104$ 